\title{
A heparin-functionalized woven stent graft for endovascular exclusion
}

DOI:

10.1016/j.colsurfb.2019.04.027

\section{Document Version}

Accepted author manuscript

Link to publication record in Manchester Research Explorer

\section{Citation for published version (APA):}

Liu, Z., Zheng, Z., Chen, K., Li, Y., Wang, X., \& Li, G. (2019). A heparin-functionalized woven stent graft for endovascular exclusion. Colloids and Surfaces B: Biointerfaces, 180, 118-126.

https://doi.org/10.1016/j.colsurfb.2019.04.027

\section{Published in:}

Colloids and Surfaces B: Biointerfaces

\section{Citing this paper}

Please note that where the full-text provided on Manchester Research Explorer is the Author Accepted Manuscript or Proof version this may differ from the final Published version. If citing, it is advised that you check and use the publisher's definitive version.

\section{General rights}

Copyright and moral rights for the publications made accessible in the Research Explorer are retained by the authors and/or other copyright owners and it is a condition of accessing publications that users recognise and abide by the legal requirements associated with these rights.

\section{Takedown policy}

If you believe that this document breaches copyright please refer to the University of Manchester's Takedown Procedures [http://man.ac.uk/04Y6Bo] or contact uml.scholarlycommunications@manchester.ac.uk providing relevant details, so we can investigate your claim.

\section{OPEN ACCESS}




\section{Accepted Manuscript}

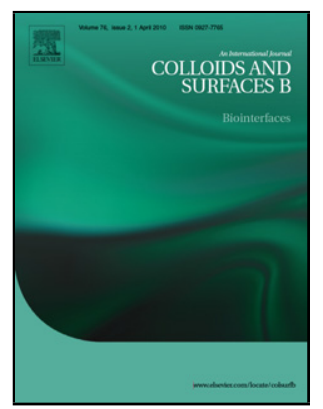

Title: A heparin-functionalized woven stent graft for endovascular exclusion

Authors: Zekun Liu, Zhaozhu Zheng, Kaili Chen, Yi Li, Xiaoqin Wang, Gang Li

PII: $\quad$ S0927-7765(19)30250-4

DOI: $\quad$ https://doi.org/10.1016/j.colsurfb.2019.04.027

Reference: $\quad$ COLSUB 10151

To appear in: $\quad$ Colloids and Surfaces B: Biointerfaces

Received date: 21 December 2018

Revised date: $\quad 26$ March 2019

Accepted date: $\quad 12$ April 2019

Please cite this article as: Liu Z, Zheng Z, Chen K, Li Y, Wang X, Li G, A heparinfunctionalized woven stent graft for endovascular exclusion, Colloids and Surfaces B: Biointerfaces (2019), https://doi.org/10.1016/j.colsurfb.2019.04.027

This is a PDF file of an unedited manuscript that has been accepted for publication. As a service to our customers we are providing this early version of the manuscript. The manuscript will undergo copyediting, typesetting, and review of the resulting proof before it is published in its final form. Please note that during the production process errors may be discovered which could affect the content, and all legal disclaimers that apply to the journal pertain. 
A heparin-functionalized woven stent graft for endovascular exclusion

Zekun Liu ${ }^{1,2 \#}$, Zhaozhu Zheng ${ }^{1 \#}$, Kaili Chen ${ }^{2}$, Yi Li ${ }^{2}$, Xiaoqin Wang ${ }^{1 *}$, Gang $\mathrm{Li}^{1 * *}$

${ }^{I}$ National Engineering Laboratory for Modern Silk, College of Textile and Clothing Engineering, Soochow University, Suzhou 215123, China

${ }^{2}$ The School of Materials, University of Manchester, Oxford Road, Manchester, M13 9PL, UK

${ }^{\#}$ These authors have equal contributions

“Corresponding authors'email:wangxiaoqin@suda.edu.cn; tcligang@suda.edu.cn

Graphical abstract 


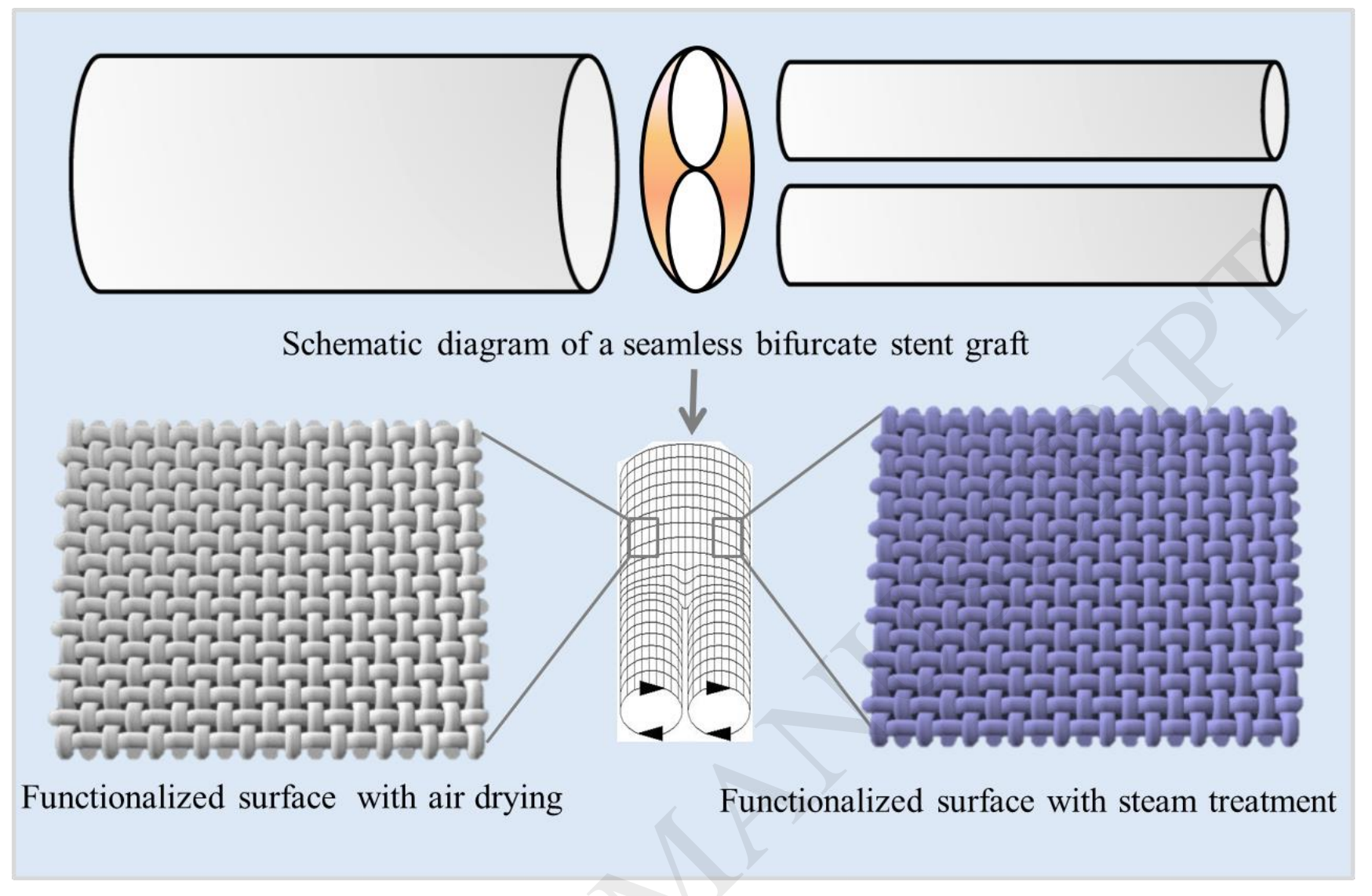

Highlights

- A novel seamless bifurcate stent graft (BSG) was developed to avoid the leakage of traditional stent graft.

- The BSG with excellent physical properties, which can meet the requirements of transplantation in endovascular graft exclusion.

- A very easy drug modification approach by coating mixtures of heparin and silk fibroin solution onto BSG surface was studies.

- The cell viability in heparin release of modified BSGs was studied and analyzed. 


\begin{abstract}
With the increase of vascular diseases in recent years, it is of importance to develop an anti-occlusion stent graft, which can meet the requirements of transplants for a long term. In this paper, we describe a silk fibroin (SF)/heparin-functionalized bifurcated stent graft (BSG) using textile forming technology. The BSGs were prototyped based on seamless weaving technology, and the surface was modified with SF-loaded heparin under steam/air treatment to improve their patency. The physical properties such as thickness, water permeability, contact angle, mechanical properties, and in vitro drug release and coagulation time of the BSGs were examined. The results showed that heparin modification can improve its coagulation time, and the water permeability resistance of the BSGs reached $1.154 \pm$ $0.854 \mathrm{~mL} /\left(\mathrm{cm}^{2} \times \mathrm{min}\right)$, while their thicknesses were just $0.085 \pm 0.004 \mathrm{~mm}$. The heparin release of the BSGs showed that the release time was prolonged upon steam treatment by means of the increase in the $\beta$-sheet structure and crystallinity of SF. The viability and attachment of human vascular smooth muscle (HVSM) cells cultured in the release of modified BSGs demonstrated that the modified BSGs could significantly inhibit the proliferation of HVSM cells. The heparin-functionalized BSG with satisfactory thickness, water permeability resistance and anti-occlusion function, which has potential applications in the treatment of vascular diseases.
\end{abstract}

Keywords: stent graft; silk fibroin; woven; heparin; surface functionalization.

\title{
1. Introduction
}

Cardiovascular disease is the leading cause of death for both men and women worldwide, and the 
incidence rate has risen significantly in recent years $[1,2]$. The traditional way to treat cardiovascular diseases is to cut off pathological blood vessels and replace them with the artificial vascular prosthesis (AVP) or with the patient's blood vessels from other parts of the body. This treatment causes severe damage to the tissues since surgical techniques for stitching blood vessels and removing pathological blood vessels are required. Patients must recuperate for several days until full recovery. Compared to the traditional treatment, endovascular graft exclusion enables less damage and faster recovery owing to the highly efficient and minimally invasive operation procedure. During endovascular graft exclusion (Fig. 1), a stent graft is guided into blood vessel through a small opening in the femoral artery, and after getting the target site, the device is stretched with a medical catheter and fixed with titanium alloy[3, 4].

Recently, various methods have been used to develop AVPs, such as freeze drying, electrostatic spinning, and textile engineering [5, 6]. In clinical, endovascular grafting surgery combining stents using textile forming technologies has been widely used for the treatment of blood vessel diseases. The artificial endovascular stent-graft should meet the requirement of ultra-thin wall thickness, excellent mechanical properties, low permeability and antithrombotic properties at the same time. Textile engineering, such as weaving, is of particular interest for developing stent grafts since they require low thickness and water permeability. Meanwhile, high mechanical strength can be fabricated and controlled by adopting various yarn materials. In fact, a stent graft needs to have a very thin thickness meanwhile with remarkable mechanical property. Artificial vascular prosthesis using freeze drying and electrostatic spinning technologies are commonly used for tissue engineering or substitutes[7, 8], which are not suitable to develop stent graft where mechanical property and minimal thickness are of importance. To 
ensure a smooth process to guide stent graft into the human femoral artery, the stent graft used in endovascular graft exclusion should have a thickness less than $0.1 \mathrm{~mm}$ [9]. Optimal permeability and mechanical properties of stent grafts can help avoid exudation and maintain the stability of devices after transplantation.However, the wall thickness and permeability of the stent graft are the two contradictory features since the thinner the wall of the stent graft, the higher the permeability. Therefore, fabricating thin stent grafts with low permeability and excellent mechanical properties is challenging. A stent graft with branched instead of linear configuration is also highly desirable for clinical applications due to the coronary arteries with branched structures.
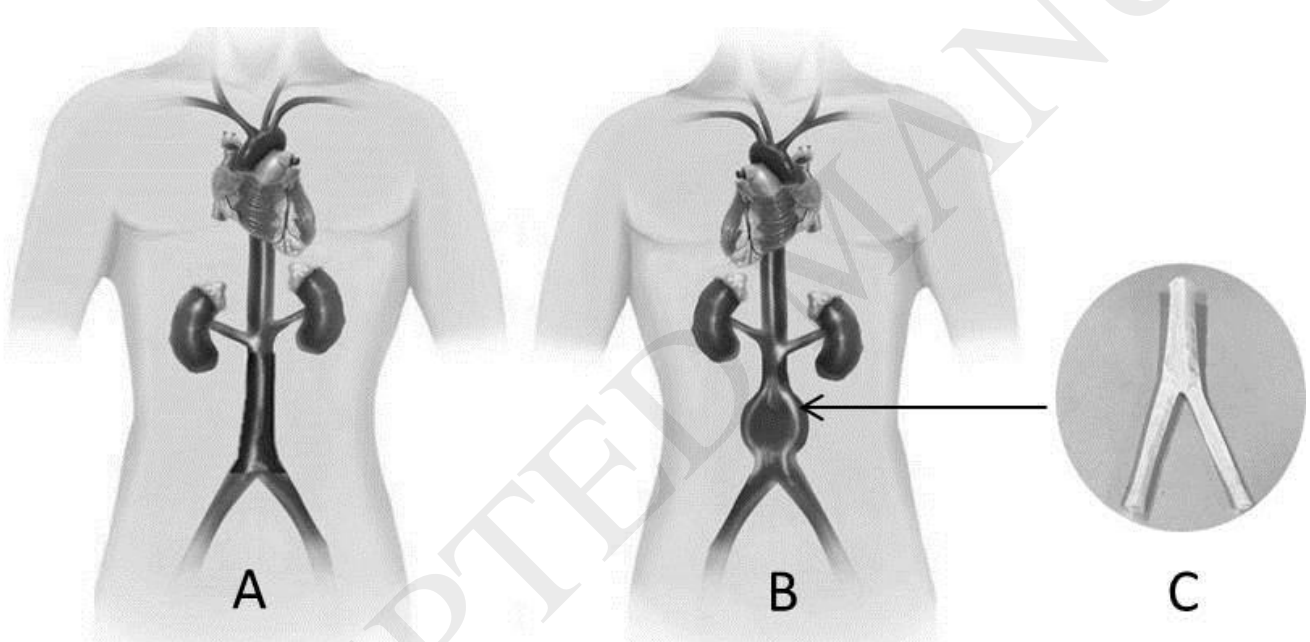

C

Fig. 1 Schematic diagram of the bifurcated stent-graft for endovascular stent graft exclusion: (A) normal blood vessel, (B) abnormal vessel, and (C) vascular prosthesis prototyped by our team.

Silk fibroin (SF) and polyethylene terephthalate (PET) have been widely used in the preparation of AVPs owing to their biocompatibility, chemical stability, and adjustable mechanical properties [10-13]. However, PET- and SF-based prostheses that lacked drug modification exhibited below par patency due to blood coagulation $[14,15]$. Alternatively, heparin, an anticoagulant, has been extensively used for 
the modification of biomaterials to enhance their anti-thrombus activity[16-18]. Moreover, heparin inhibits the proliferation of human vascular smooth muscle (HVSM) cells [19, 20], suggesting that occlusion of vascular prosthesis due to the over-proliferation of HVSM cells can be prevented using heparin on or near the material surface. Thus, much research has been conducted to achieve stable and high-quantity immobilization of heparin on vascular prosthesis as well as its sustained release from the surface. Commonly used techniques to immobilize heparin include layer-by-layer coating via electrostatic interaction [21-23] and physical absorption-based approaches [24, 25]. Unfortunately, these methods are technically difficult and time-consuming, and more importantly, heparin loading and release from the coating material matrix are challenging to control since most biomaterials used for coating need either chemical crosslinkers or organic solvents during processing, which would be detrimental to the bioactivity and function of heparin. Thus, biomaterials with crosslinking mechanisms free of harmful solvents and chemicals are highly desired to immobilize heparin on the surface of the vascular prosthesis.

SF has been widely used to fabricate and modify medical devices [26-28]. A variety of SF materials, such as films, hydrogels, particles, and sponges can be fabricated by changing $\mathrm{pH}$, salt concentration, temperature, and shear force (agitation, sonication) so that the structural transition from random coil to $\beta$-sheet occurs, leading to self-assembly and solidification of SF due to hydrogen bonds and hydrophobic interactions. Owing to high crystallinity, excellent mechanical properties, high enzymatic degradation, and excellent biocompatibility, we hypothesize that SF biomaterials are ideal carriers to 
encapsulate and release bioactive elements, ranging from small molecules to macromolecule drugs [29, 30].

In this study, we designed and prototyped a novel bifurcated stent graft (BSG) with SF-encapsulated heparin as the surface coating. The graft was further treated by water vapor to achieve sustained release of heparin from the SF coating and in turn to improve the patency. The physical properties, secondary structure, and in vitro drug release of the BSGs were examined. The attachment and viability of HVSM cells cultured in the releases of modified BSGs were evaluated.

\section{Materials and methods}

\subsection{Materials}

Silk yarns filaments (Bombyx mori) were purchased from Xiehe Silk Co., Ltd. (Zhejiang, China), including degummed silk (DS) as well as raw silk (RS). PET yarns (monofilament and multifilament) were purchased from New Material Technology Co., Ltd. (Jiaxing, China). The silk and PET yarns were 2.4 tex. $\mathrm{LiBr}, \mathrm{Na}_{2} \mathrm{CO}_{3}$, picric acid, carmine, PBS, and dialysis tubes were supplied by Sinopharm Chemical Reagent Co., Ltd. (Shanghai, China). Heparin (average $M_{w}=15000$, sodium salt) was purchased from Aladdin (Shanghai, China). Silk fibroin solution for heparin coating was prepared using RS. Cell culture medium, cell staining, and other reagents were purchased from Life Technology (Grand Island, NY). HVSM cells were purchased from Fenghui biotechnology Co., Ltd. (Hunan, China).

\subsection{Fabrication of BSGs}


The factorial design was performed for the BSG fabrication. Three factors (basic weave, density, and materials), each factor having three levels, were studied. For the basic weave, three levels of plain, $2 / 2$ twill and 3/1 twill were used; for the density of warp/10 cm×weft/10 cm, 1100 inserts $\times 800$ inserts, 1100 inserts $\times 1400$ inserts, and 1100 inserts $\times 2000$ inserts were used; for the warp $\times$ weft material, $1 f$ PET $\times 12 f$ PET, 1f PET $\times$ DS, and RS $\times$ DS were used. The design and specification of the BSGs are given in Table 1.

Table 1. Factorial design of the BSGs.

\begin{tabular}{|c|c|c|c|c|}
\hline Samples & Fabric weaves & $\begin{array}{l}\text { Materials } \\
\text { (warp } \times \text { weft) }\end{array}$ & $\begin{array}{l}\text { Warp } \times \text { weft counts } \\
(\mathrm{D} / \text { filament count })\end{array}$ & $\begin{array}{l}\text { Fabric counts } \\
(\mathrm{ends} / 10 \mathrm{~cm} \times \text { picks } / 10 \mathrm{~cm})\end{array}$ \\
\hline $\mathrm{a}$ & & PET $\times$ PET & $22 \mathrm{D} / 1 \mathrm{f} \times 22 \mathrm{D} / 12 \mathrm{f}$ & $1100 \times 800$ \\
\hline $\mathrm{d}$ & & $\mathrm{PET} \times \mathrm{DS}$ & $22 \mathrm{D} / 1 \mathrm{f} \times 22 \mathrm{D} / 12 \mathrm{f}$ & $1100 \times 1400$ \\
\hline $\mathrm{g}$ & 1/1 plain & $\mathrm{RS} \times \mathrm{DS}$ & $22 \mathrm{D} / 12 \mathrm{f} \times 22 \mathrm{D} / 12 \mathrm{f}$ & $1100 \times 2000$ \\
\hline $\mathrm{b}$ & & $\mathrm{PET} \times \mathrm{DS}$ & $22 \mathrm{D} / 1 \mathrm{f} \times 22 \mathrm{D} / 12 \mathrm{f}$ & $1100 \times 800$ \\
\hline e & & $\mathrm{RS} \times \mathrm{DS}$ & $22 \mathrm{D} / 12 \mathrm{f} \times 22 \mathrm{D} / 12 \mathrm{f}$ & $1100 \times 1400$ \\
\hline $\mathrm{h}$ & $1 /$ & PET $\times$ PET & $22 \mathrm{D} / 1 \mathrm{f} \times 22 \mathrm{D} / 12 \mathrm{f}$ & $1100 \times 2000$ \\
\hline c & & $\mathrm{RS} \times \mathrm{DS}$ & $22 \mathrm{D} / 12 \mathrm{f} \times 22 \mathrm{D} / 12 \mathrm{f}$ & $1100 \times 800$ \\
\hline$f$ & & PET $\times$ PET & $22 \mathrm{D} / 1 \mathrm{f} \times 22 \mathrm{D} / 12 \mathrm{f}$ & $1100 \times 1400$ \\
\hline 1 & $2 / 2$ twill & PET $\times$ DS & $22 \mathrm{D} / 1 \mathrm{f} \times 22 \mathrm{D} / 12 \mathrm{f}$ & $1100 \times 2000$ \\
\hline
\end{tabular}

\subsection{Post-processing of BSGs}


After preparation, the samples were subjected to certain treatments to obtain the final BSGs. The three types of warp $\times$ weft materials-SF-based, pure PET-based, and PET/SF-combined BSGs-possess different material composition and properties; thus, they were treated differently. First, the BSGs were cleaned by ultrasonication for $30 \mathrm{~min}$ in distilled water to remove impurities. Next, the PET/SF-combined and pure SF-based BSGs were degummed with $0.05 \%$ (w/w) $\mathrm{Na}_{2} \mathrm{CO}_{3}$ solution at 98 ${ }^{\circ} \mathrm{C}$ for two and four times, respectively, to remove sericin. Degumming time was determined by picric acid-carmine dye solution, as reported elsewhere [31]. Sericin was completely removed when the fibers turned into light yellow that was in stark contrast with the dark brown color of the untreated BSGs.

\subsection{Heparin modification}

The surfaces of the selected BSGs were modified with heparin by dip coating using SF/heparin blend solution. The schematic diagram of the modification process is shown in Fig. 2. Silk cocoon was boiled in $0.02 \mathrm{M} \mathrm{Na}_{2} \mathrm{CO}_{3}$ for $1 \mathrm{~h}$ that was followed by three times of washing. The degummed SF fibers were dried and stored in a sealed bag at room temperature before use. Next, 9.3 M LiBr was poured into a glass beaker containing degummed SF fibers to obtain SF solution. The concentration of $\mathrm{SF}$ in $\mathrm{LiBr}$ solution was $20 \%(\mathrm{w} / \mathrm{v})$. The beaker was sealed and incubated at $60{ }^{\circ} \mathrm{C}$ for $4 \mathrm{~h}$, and the viscous SF concentration obtained was dialyzed against ultrapure water for $48 \mathrm{~h}$ while water was changed six times during the process. The SF solution obtained that had a concentration of $10 \%(\mathrm{w} / \mathrm{v})$ was determined by drying and weighing the volume of solution. The purified SF solution was stored at $4{ }^{\circ} \mathrm{C}$ and diluted with ultrapure water to desired concentrations before use. For surface modification, the BSG (g) was immersed in a solution containing $1 \%(\mathrm{w} / \mathrm{v}) \mathrm{SF}$ and $2 \mathrm{mg} / \mathrm{ml}$ heparin for $60 \mathrm{~min}$ at room temperature 
before the sample was taken out and air-dried in a fume hood. The dried samples were placed in an oven $\left(60^{\circ} \mathrm{C}\right)$ and exposed to water vapor for $2 \mathrm{~h}$ to induce the $\beta$-sheet structure of SF.

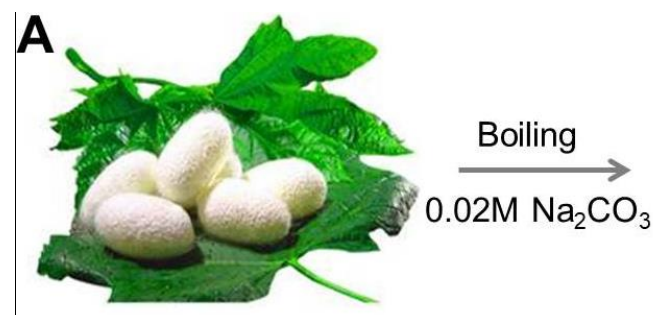

Silk cocoon

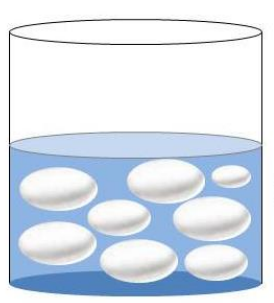

Sericin extraction
B

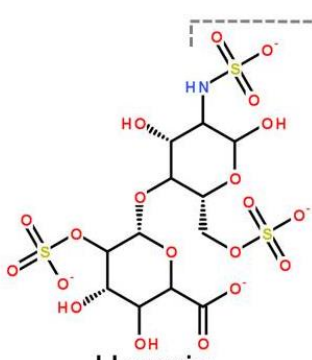

Heparin

C
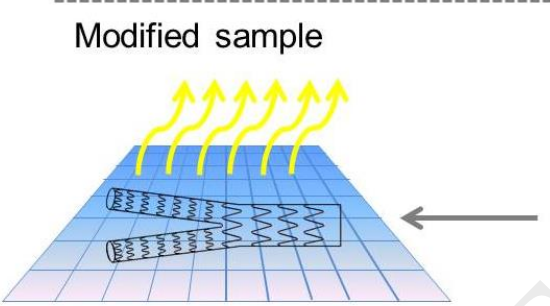

Air drying

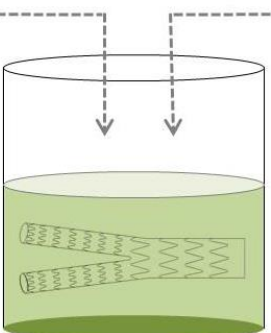

Mixture solution coating onto sample
Winding

Wash and dry

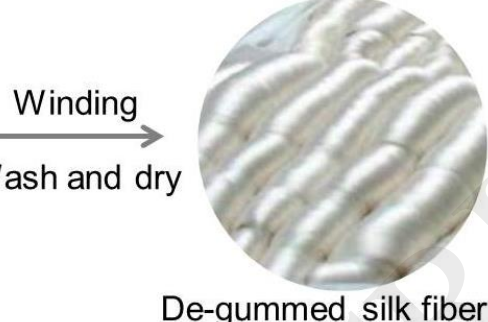

De-gummed silk fiber

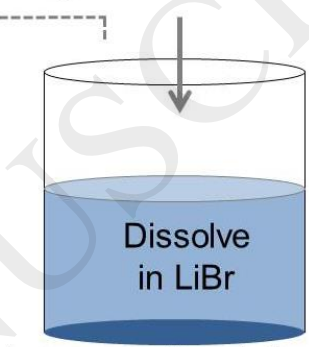

Aqueous silk solution

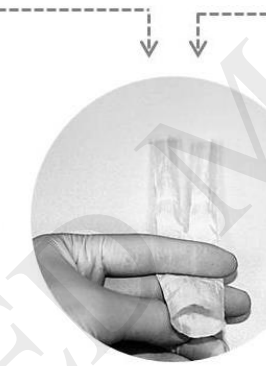

Modified sample

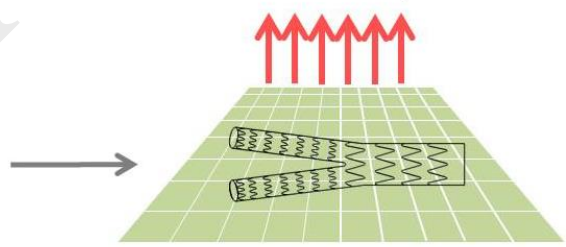

Water steam

Fig. 2 Heparin modification process of BSG: (A) degumming of silk cocoon, (B) BSG coating via the mixture of SF and heparin, (C) heparin-coated BSG with air drying and water steam treatments.

\subsection{Cell culture}

HVSM cells were cultured in the release of heparin-modified BSGs with air drying and steam treatment in 24-well plates (10000 cells $\mathrm{cm}^{-2}$ ) for $72 \mathrm{~h}$. Releases of modified BSGs were obtained at $2 \mathrm{~h}, 8 \mathrm{~h}$, and 144 h. HVSM cells were also cultured in PBS to serve as the control. Cell viability at different time points was determined using a commercial kit (CCK-8, Bio-TEK instrument, USA). The cells after 
CCK-8 staining were washed twice with PBS buffer, $\mathrm{pH} 7.4$, incubated in $50 \mathrm{~mL}$ serum-free culture medium supplemented with $1.87 \mathrm{ng} / \mathrm{mL}$ calcium AM (Dojindo, Shanghai, China) for $20 \mathrm{~min}$ at $37{ }^{\circ} \mathrm{C}$ and observed under a fluorescence microscope (Axio Vert.A1, Carl Zeiss, Germany). The total cell metabolic was represented by fluorescence intensity of Alamar Blue (Ex560/Em590).

\subsection{Characterization}

The fiber arrangement on BSG surfaces was characterized by ultra-well deep microscope ((VHX-100/VW-6000/5000, Keyence, Japan)). The wall thickness of the textile-based stent graft is tested (YG-B 141D, Guo Liang, China) under $981 \mathrm{~Pa}$ for the testing area of $0.5 \mathrm{~cm}^{2}$ according to the standard protocol (ISO7198: 2016). A thickness of less than $0.10 \mathrm{~mm}$ was intended [9, 31]. Water permeability test was done under a hydrostatic pressure of $120 \mathrm{mmHg}$, and the water permeability of BSG less than $300 \mathrm{ml} /\left(\mathrm{cm}^{2} \times \mathrm{min}\right)$ was intended to meet the requirements of transplantation. The contact angles of untreated and modified BSG were tested via a surface contact angle tester (Krüss Company, Germany) and the water drop is $0.6 \mu \mathrm{L}$. Diameter tensile strength and bursting strength of the samples were determined using a mechanical testing instrument (INSTRON-3365, Instron, America). The test speed of tensile was $100 \mathrm{~mm} / \mathrm{min}$, while the speed of bursting was $50 \mathrm{~mm} / \mathrm{min}$. The diameter tensile strength and bursting strength were calculated using Equations (1) and (2), respectively.

$$
\mathrm{F}=2 \mathrm{~T} / \pi \mathrm{D}
$$

where D (mm) and T $(\mathrm{N})$ are the diameter and breaking force of BSG, respectively, and F (N/mm) is its diameter tensile strength. 


$$
\mathrm{F}=\mathrm{T} / \pi \mathrm{r}^{2}
$$

where $\mathrm{r}(\mathrm{mm})$ and $\mathrm{T}(\mathrm{N})$ are the semi-diameter of the test probe and the bursting force of BSG, respectively, and $\mathrm{F}(\mathrm{N} / \mathrm{mm})$ is the bursting strength.

The bending stiffness of a textile-based stent graft can be evaluated for the flexibility of stent graft[32]. The bending stiffness of BSG was characterized by a Shirley Stiffness Tester and calculated using Equations (3).

$$
\mathrm{B}=\mathrm{ML}^{3} \frac{\cos \left(\frac{\theta}{2}\right)}{8 \tan \theta}
$$

where $\mathrm{B}(\mathrm{mg} \mathrm{cm})$ is bending stiffness, $\mathrm{M}\left(\mathrm{mg} / \mathrm{cm}^{2}\right)$ and $\mathrm{L}(\mathrm{cm})$ are the weight per unit area and bending length respectively. The $\theta\left(41.5^{\circ}\right)$ is the given angle in the Shirley Stiffness Tester.

Heparin release in vitro was performed by cutting heparin-modified BSGs into pieces, then immersed into PBS at $37{ }^{\circ} \mathrm{C}$ with shaking. Heparin detection was conducted by toluidine blue based on the mothed of our previous study [33]. Briefly, the standard curve was gained via different concentrations of heparin and then used to calculate the released heparin. An automatic coagulometer (Stago Compact, Stago, France) was used to measure the automated partial thromboplastin time (APTT) and prothrombin time of untreated and modified BSGs. Briefly, the BSGs in pieces were immersed in PBS for $12 \mathrm{~h}$ and the PBS was changed twice during the process. Then the samples were incubated in human plasma at $37^{\circ} \mathrm{C}$ for $2 \mathrm{~h}$. Finally, the ATPP and PT of the plasma were measured. Crystal structure of the coated membrane by an X-ray diffractometer (X'Pert-Pro MPD, PANalytical BV, Almelo, Netherlands). X-ray diffraction patterns were obtained using $\mathrm{Cu} \mathrm{K \alpha}$ wavelength of $0.154 \mathrm{~nm}$ for the 
range of $5-60^{\circ}$, voltage of $40 \mathrm{kV}$, and current of $35 \mathrm{~mA}$ at a scanning rate of $5^{\circ} \mathrm{min}^{-1}[34]$. Besides, Fourier Transform Infrared Spectroscopy (Nicolet 5700, Thermo Electron Corp, Waltham, MA) was used to detect the secondary structure, and the wavenumbers were set from 4000 to $400 \mathrm{~cm}^{-1}$ during 32 scans with $2 \mathrm{~cm}^{-1}$ resolution[35].

\subsection{Statistical analysis}

The data collected for various heparin-modified BSGs were subjected to one-way ANOVA analysis. The statistical difference between two groups of data is significant when $\mathrm{p}<0.05$.

\section{Results and discussion}

\subsection{Fabrication of BSGs}

The warp and weft yarns of plain, 2/2 twill and 3/1 twill can be seen in Fig. 3A, where a, b and c represent the plain 2/2 twill and 3/1 twill weave of BSGs. During fabrication, one shuttle was used for both the main trunk part and the transition part, while two shuttles were used for branch part in that each branch required one shuttle. The weaving process and one of the finished samples are shown in Fig. 3B-D. We encountered some problems during the weaving process, such as electrostatic attraction and unmatched warp tension. Electrostatic attraction might raise the risk of getting snapped warp yarns; thus, it affects the quality of the final BSG. The problem was solved by using water or antistatic agent to treat all yarns prior to the weaving process. Unmatched warp tension, which could affect the uniformity of the BSGs, was overcome by balancing weights on the warp yarn. After preparation, all BSGs were either cleaned without degumming or cleaned and degummed, and then they were dried in an oven. 


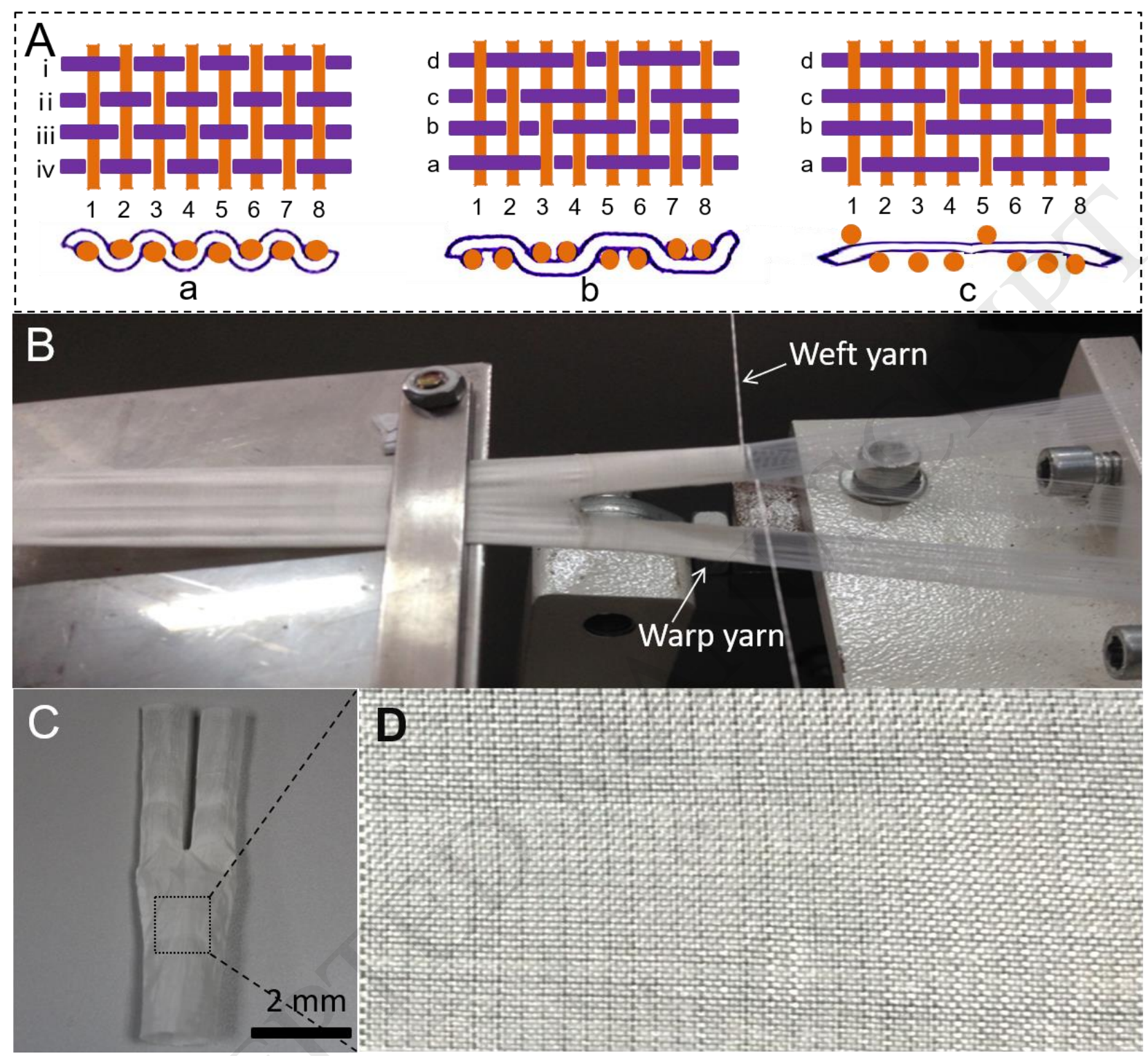

Fig. 3 Weave design and fabrication of BSGs: (A) fabric structure diagrams of plain (a), 2/2 twill (b), and 3/1 twill weave (c), (B-D) photos showing the weaving process, a finished sample, and the surface of the BSG.

The fiber arrangements of all the finished BSGs are shown in Fig. 4. The sample with a plain structure design showed a more uniform surface compared with that of the $3 / 1$ twill weave and $2 / 2$ twill weave samples. As expected, the BSGs with lower fabric densities showed more visible pores (a, b, c) compared with those with higher densities. 


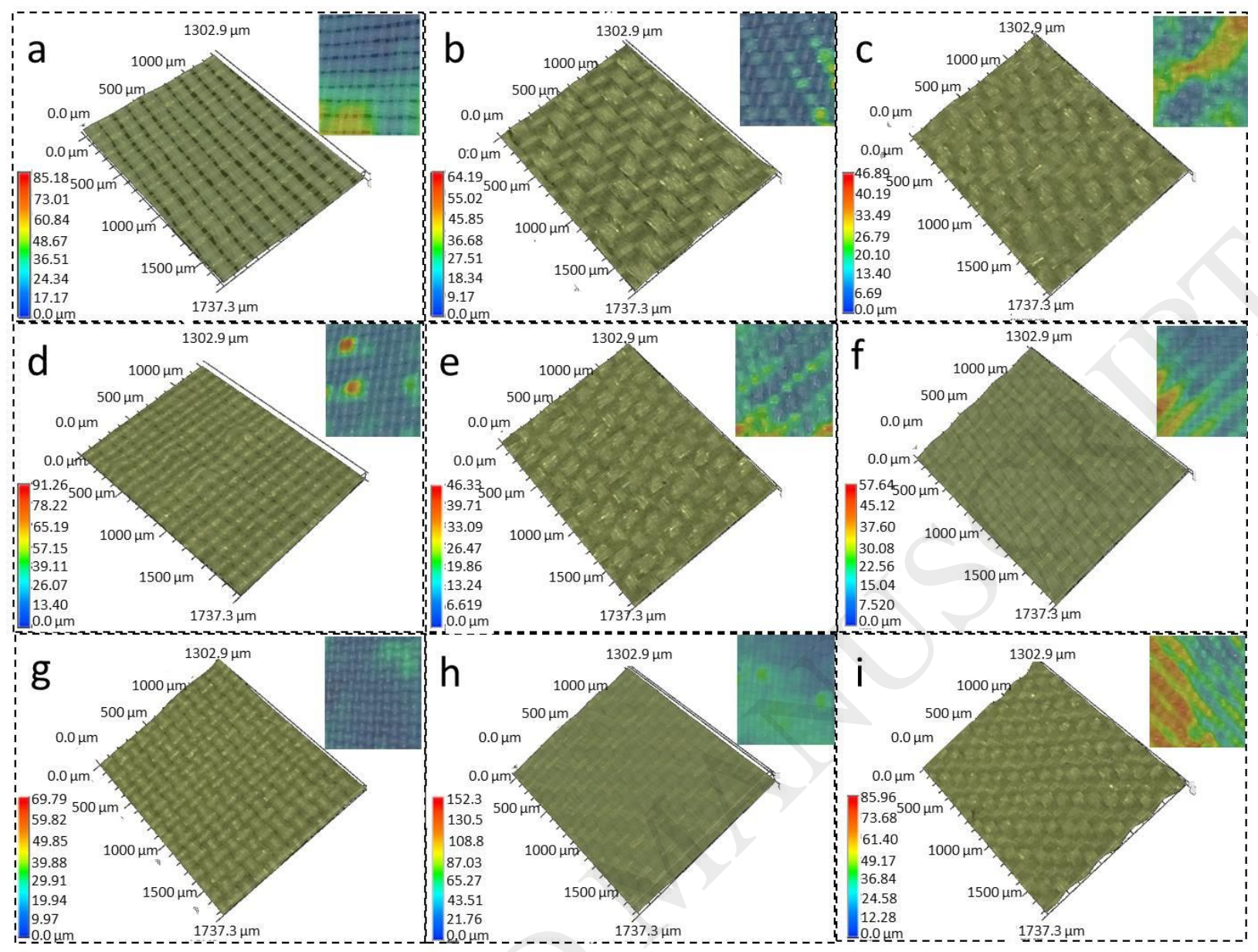

Fig. 4 Surface fiber arrangements of the BSGs shown in Table 1.

\subsection{Physical properties}

The thickness of BSGs is a significant factor that determines the stent grafting procedure during surgery.

The thicknesses of all the BSGs ranged from $\sim 0.06 \mathrm{~mm}$ to $\sim 0.125 \mathrm{~mm}$, as shown in Fig. 5A. Pure

PET-based BSGs (a, f, h) had relatively lower thicknesses compared with the corresponding pure

SF-based BSGs (c, e, g). The difference in material properties of PET and silk yarns resulted in different cross weave highness and ultimately different thicknesses of the BSGs. Besides, the thickness increased for the pure PET-based BSGs (a, f, h) when their weft density increased from 800 picks/10 cm to 2000 picks/10 cm. This trend, however, did not appear for the pure SF-based BSGs (c, e, g). The PET and 
SF-combined BSGs (b, d, i) had significantly diverse thicknesses of $0.10 \mathrm{~mm}, 0.07 \mathrm{~mm}$, and $0.13 \mathrm{~mm}$, respectively. After heparin modification, a statistically significant difference $(\mathrm{p}<0.05)$ was recorded between $\mathrm{g}$ and $\mathrm{g}_{1}$ (with air drying) as well as $\mathrm{g}_{2}$ (with steam treatment). This difference occurred due to increasing attachments of SF and heparin onto the surface of BSG during the coating process. After modification by SF and heparin, the thicknesses of the BSGs $\left(g_{1}\right.$ and $\left.g_{2}\right)$ significantly increased but were still less than $0.10 \mathrm{~mm}$, indicating that the heparin-modified BSGs can still meet the thickness requirement for transplantation.
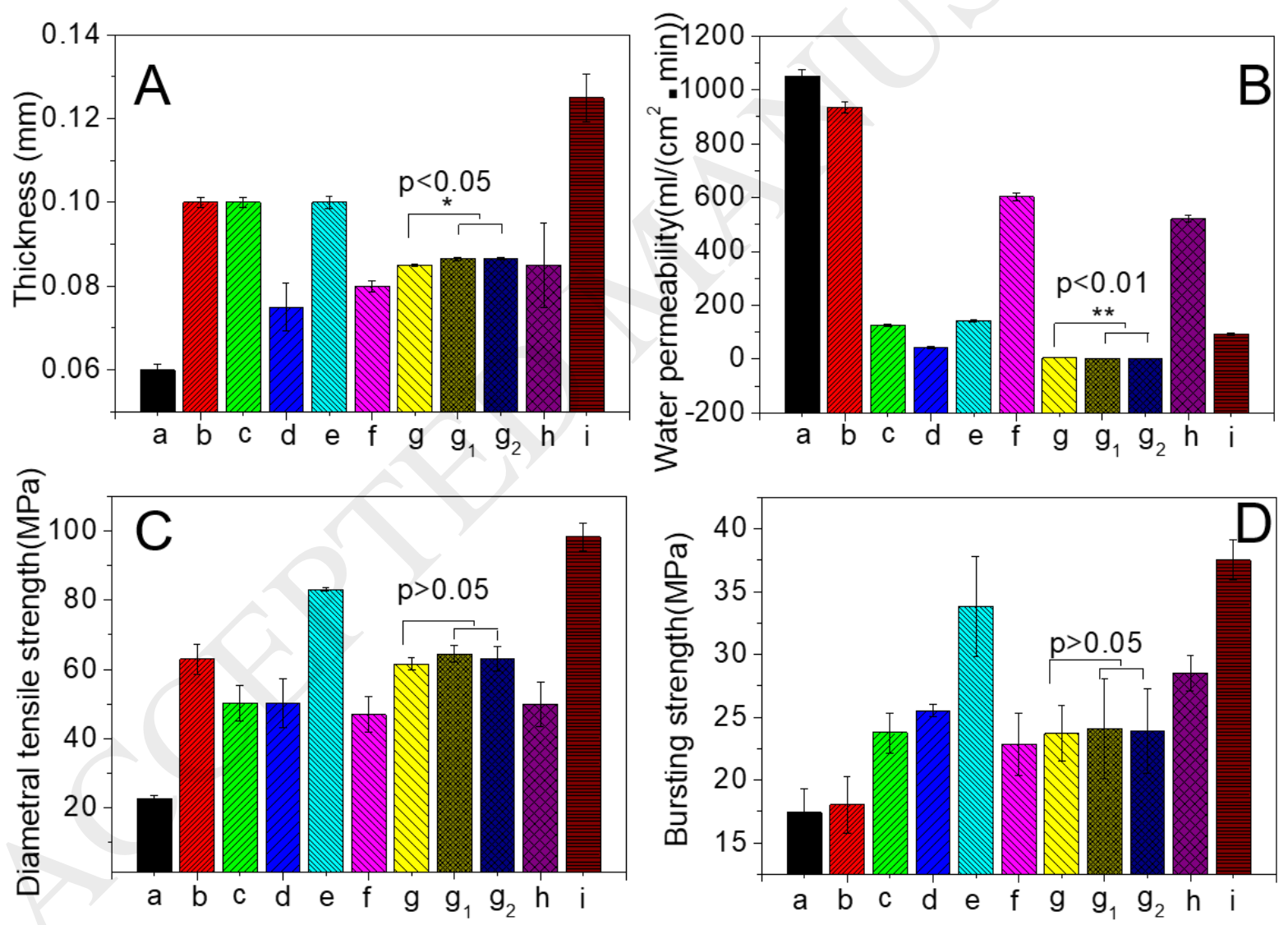

Fig. 5 Physical properties of BSGs: (A) thickness, (B) water permeability, (C) diametral tensile strength, and (D) bursting strength. (a-i) The BSGs without modification, $\left(\mathrm{g}_{1}\right)$ modified with air drying, and $\left(\mathrm{g}_{2}\right)$ steam treatment.

Water permeability resistance is one of the most important factors that reflect the anti-blood 
leakage potential of a stent graft. The water permeability resistance of the BSGs (a, b, f, h) exceeded 300 $\mathrm{ml} /\left(\mathrm{cm}^{2} \times \mathrm{min}\right)$, whereas it was less than $300 \mathrm{ml} /\left(\mathrm{cm}^{2} \times \min \right)$ for the others $(\mathrm{c}, \mathrm{d}, \mathrm{e}, \mathrm{g}, \mathrm{i})($ Fig. 5B). The water permeability resistance of the BSGs made of pure PET, irrespective of their fabric weave and fabric density, were higher than $500 \mathrm{ml} /\left(\mathrm{cm}^{2} \times \mathrm{min}\right)$. In contrast, the water permeability resistance values of the pure SF-based BSGs were less than $200 \mathrm{ml} /\left(\mathrm{cm}^{2} \times \mathrm{min}\right)$, and sample $\mathrm{g}$ (pure SF-based, plain weave with a density of $1100 / 10 \mathrm{~cm} \times 2000 / 10 \mathrm{~cm}$ ) showed the lowest water permeability resistance of 5.19 $\mathrm{ml} /\left(\mathrm{cm}^{2} \times \mathrm{min}\right)$. For the BSGs made from SF and PET (sample b, d and I), medium-level water permeability resistances of approximately $940 \mathrm{ml} /\left(\mathrm{cm}^{2} \times \mathrm{min}\right), 45 \mathrm{ml} /\left(\mathrm{cm}^{2} \times \mathrm{min}\right)$, and $95 \mathrm{ml} /\left(\mathrm{cm}^{2} \times \mathrm{min}\right)$ were obtained, respectively. The significant difference between the water permeability resistance values of pure PET-based BSGs and pure SF-based BSGs likely occurred due to the differences in their material properties. PET is known as a hydrophobic material, which has a lower water binding ability [36]. As a result, water leaks out from the PET-based BSG during water permeability test. In contrast, SF contains a great number of amino and carboxyl groups [37], providing an excellent water-binding ability and resulting in lower water permeability resistance for the SF-based BSG.

The water permeability resistance values of heparin-modified samples ( $g_{1}$ and $\left.g_{2}\right)$ has been improved very significantly $(\mathrm{p}<0.01)$ compared with that of unmodified BSG $(\mathrm{g})$. After modification, the water permeability was 1.56 (with air drying) and 1.15 (with steam treatment) $\mathrm{ml} /\left(\mathrm{cm}^{2} \times \mathrm{min}\right.$ ). SF and heparin coating on the BSG surface not only increased the steric hindrance but also changed surface hydrophilicity; thus, it promoted water-surface interaction, resulting in decreased water permeability resistance. 
The two key parameters-diameter tensile strength and bursting strength were investigated for mechanical characterization of the BSGs. The diameter tensile strength indicates whether BSG can bear the overall force from the supporting titanium alloy, whereas the bursting strength reflects the highest force that BSG can withstand at specific points along the stent. The diameter tensile strengths of the BSGs ranged from approximately 20 to $100 \mathrm{MPa}$, while most samples had a diameter tensile strength of approximately $50 \mathrm{MPa}$ (Fig. 5C). The bursting strength was determined to be between approximately 17.5 MPa and 37.5 MPa for all the BSGs (Fig. 5D). The diameter tensile strength and bursting strength for the unmodified BSG $(\mathrm{g})$ and modified BSGs ( $\mathrm{g}_{1}$ and $\left.\mathrm{g}_{2}\right)$ showed no significant difference $(\mathrm{p}>0.05)$.

The nature of individual yarns of the fabric material played a predominant role in determining diameter tensile strength compared with the effect of fabric density and fabric weave (Fig. 5C). On the other hand, material density rather than the fabric material is the most influential factor that determined the bursting strength (Fig. 5D). The result is in agreement with the fact that bursting strength reflects the mechanical property of the BSGs locally; therefore, the fabric with a higher density could bear higher pressure from the probe. Heparin modification did not change the diameter tensile strength and bursting strength, indicating that the limited amount of SF and heparin coating did not alter the mechanical properties of BSGs.

The bending stiffness of untreated and modified BSGs was tested to reflect its flexibility. Shirley Stiffness Tester, which can be seen in Fig. 6A, and equation (3) was applied to calculate the bending stiffness of untreated and modified BSGs. The results can be seen in Fig 6B that bending stiffness of modified BSGs significantly increases after air drying $(\mathrm{p}<0.05)$ and steam treatment $(\mathrm{p}<0.01)$, 
illustrating that the flexibility of modified BSG decreases as a result of the SF/heparin coating on the surface. The bending stiffness of modified BSGs with air drying and steam treatment is still only 64.5 $\pm 7.64 \mathrm{mg} \mathrm{cm}$ and $103.55 \pm 18.27 \mathrm{mg} \mathrm{cm}$, which has remarkable flexibility.
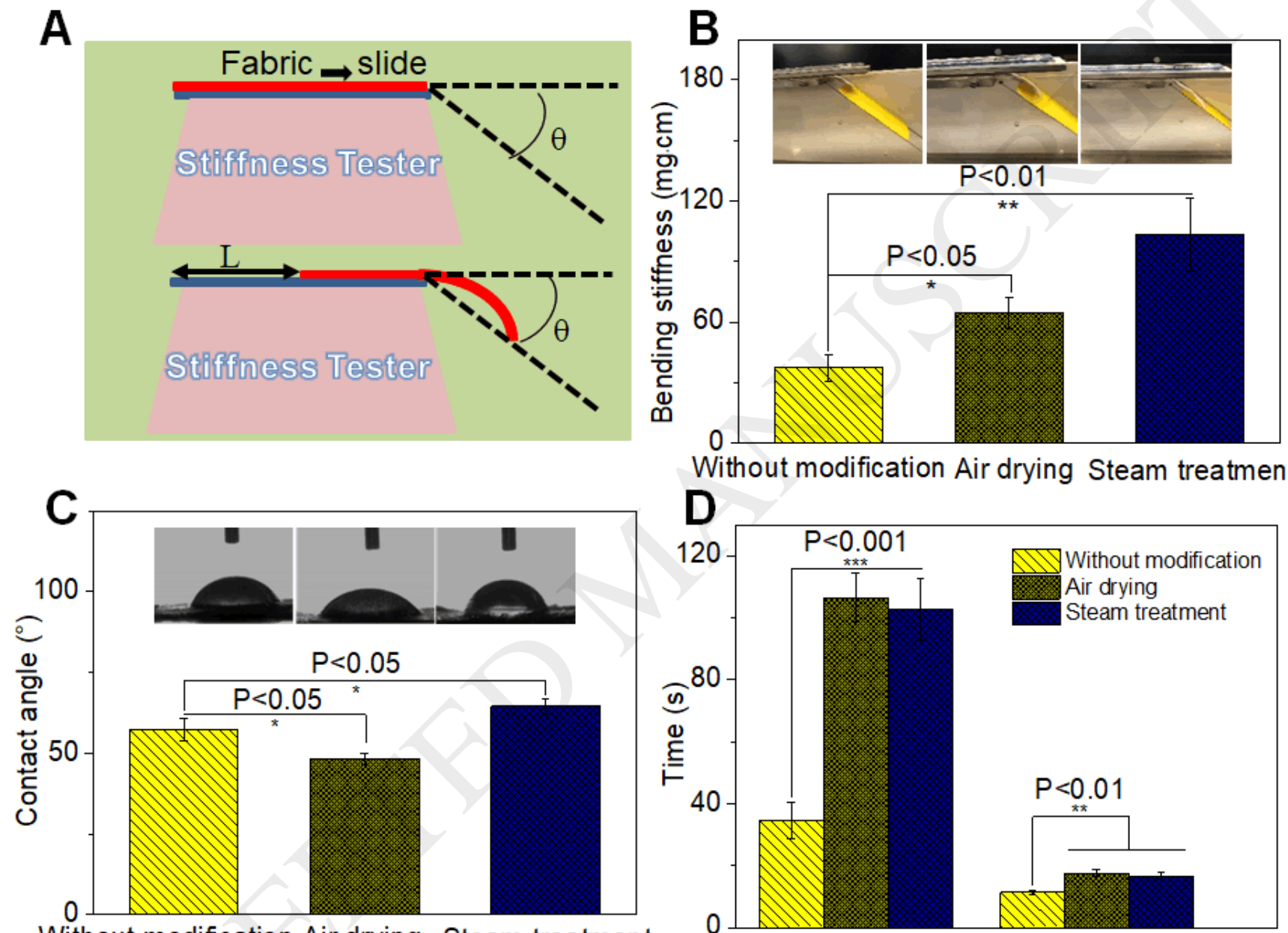

Without modification Air drying Steam treatment

Without modification Air drying Steam treatment

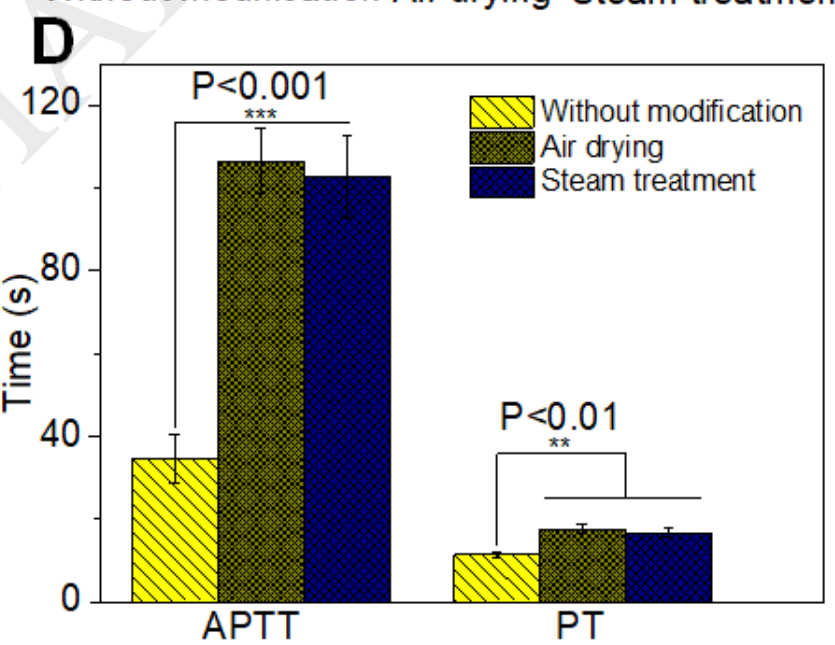

Fig. 6 Physical properties of untreated and modified BSGs: (A) schematic diagram of Shirley Stiffness Tester, (B) bending stiffness, (C) surface contact angle, and (D) APTT and PT results.

It can be seen from Fig. 1 that the contact angle (CA) of untreated BSG is $57.35 \pm 3.6^{\circ}$, and the CAs of modified BSGs are $48.16 \pm 1.8^{\circ}$ and $64.57 \pm 2.4^{\circ}$ after modification with air and steam treatment, respectively. Furthermore, the CA significantly decreases $(p<0.05)$ and increases $(p<0.05)$ after air 
drying and steam treatment. The decreased CA can be attributed to hydrophilic groups after SF/heparin modification, because heparin and regenerative SF solution are hydrophilic[38, 39]. In contrast, the hydrophilicity of samples becomes lower after steam treatment, which is because the formation of $\beta$-sheet structure of SF during the treatment process, the $\beta$-sheet structure of SF benefits the increase of the materials' CA. This result is consistent with previous study[40]. Coagulation time in vitro can be represented by APTT and PT, which is showed in Fig. 6D. The ATPP of untreated BSG is $34.63 \pm 5.84 \mathrm{~s}$, and it significantly increases $(\mathrm{p}<0.001)$ to $106.54 \pm 7.89 \mathrm{~s}$ and $102.67 \pm 9.73 \mathrm{~s}$ after air drying and steam treatment, respectively. Similarly, the PT rises significantly ( $<<0.01$ ) from $11.32 \pm 0.76 \mathrm{~s}$ to $17.56 \pm 1.24 \mathrm{~s}$ and $16.67 \pm 0.98 \mathrm{~s}$ after air drying and steam treatment, respectively. The results can be attributed to the heparin modification, endowing the BSG with anti-coagulant function[41, 42].

\subsection{Heparin release and HVSM cells viability of modified BSGs}

Fig. 7A shows the cumulative heparin release from the heparin-modified BSGs with air drying and steam treatment. The amount of heparin released from the samples increased with the duration of release time. Only $60 \%$ heparin was released after $200 \mathrm{~h}$ for BSG with steam treatment, while nearly $100 \%$ heparin was released after $50 \mathrm{~h}$ for BSG with air drying treatment. Fig. 7B and Fig. 7C shows FTIR spectra and XRD patterns of the two types of heparin-modified BSGs. The two peaks at $1635 \mathrm{~cm}^{-1}$ and $1650 \mathrm{~cm}^{-1}$ appeared for both the modified BSGs and the steam-treated BSGs in contrast to the air-dried BSGs. XRD patterns showed peaks at $20.5^{\circ}$ and $21^{\circ}$ for the steam-treated and the air-dried BSGs, respectively, with the former being sharper than that of the latter. This result is agreement with the FTIR results, indicating that the structure of SF coating has changed via steam treatment. Fig. 7D shows the 
secondary structure content of SF in the heparin-modified BSGs after Fourier deconvolution analysis. The $\beta$-sheet content of SF in the BSG was found to be $33.24 \%$ among all secondary structures before treatments and increased to $38.96 \%$ after steam treatment as expected [43]. The percentages of the alpha-helical structure of the heparin-modified BSGs with and without steam treatment were found as $9.35 \%$ and $10.48 \%$, respectively. The $\beta$-sheet and helix percentages of the modified BSGs were significantly promoted $(\mathrm{p}<0.001)$ and decreased, respectively, after steam treatment in comparison to those of the air-dried BSGs.

The heparin-modified BSG after air drying showed a relatively fast and complete release within $120 \mathrm{~h}$ (Fig. 7A). However, the heparin-modified BSGs with steam treatment showed a sustained release, with about $60 \%$ of heparin being released within this period $(120 \mathrm{~h})$, and the release of heparin became very slow afterward. The unreleased heparin might have been entrapped in the SF coating due to steric hindrance or binding to the SF matrix and is expected to be released by enzymatic degradation of SF during in vivo applications. This result demonstrates the vital role of $\beta$-sheet structure and crystallinity of SF for controllable drug release and is consistent with the results from previous studies [44].

The metabolic activity of HVSM cells during the heparin release of the modified BSGs was determined by Alamar Blue cell viability reagent, as can be seen in Fig. 7E. The heparin release (2 h) of the modified BSGs significantly inhibited cell viability, and a similar inhibiting effect was also found when the release time reached $8 \mathrm{~h}$. When the release medium collected at $144 \mathrm{~h}$ was added to the cell culture, a significant inhibiting effect was still observed for the steam-treated BSGs (p $<0.001)$, suggesting the modified BSG with steam treatment had a longer inhibitory effect on HVSM cells in 
comparison to that of the air-dried BSGs.
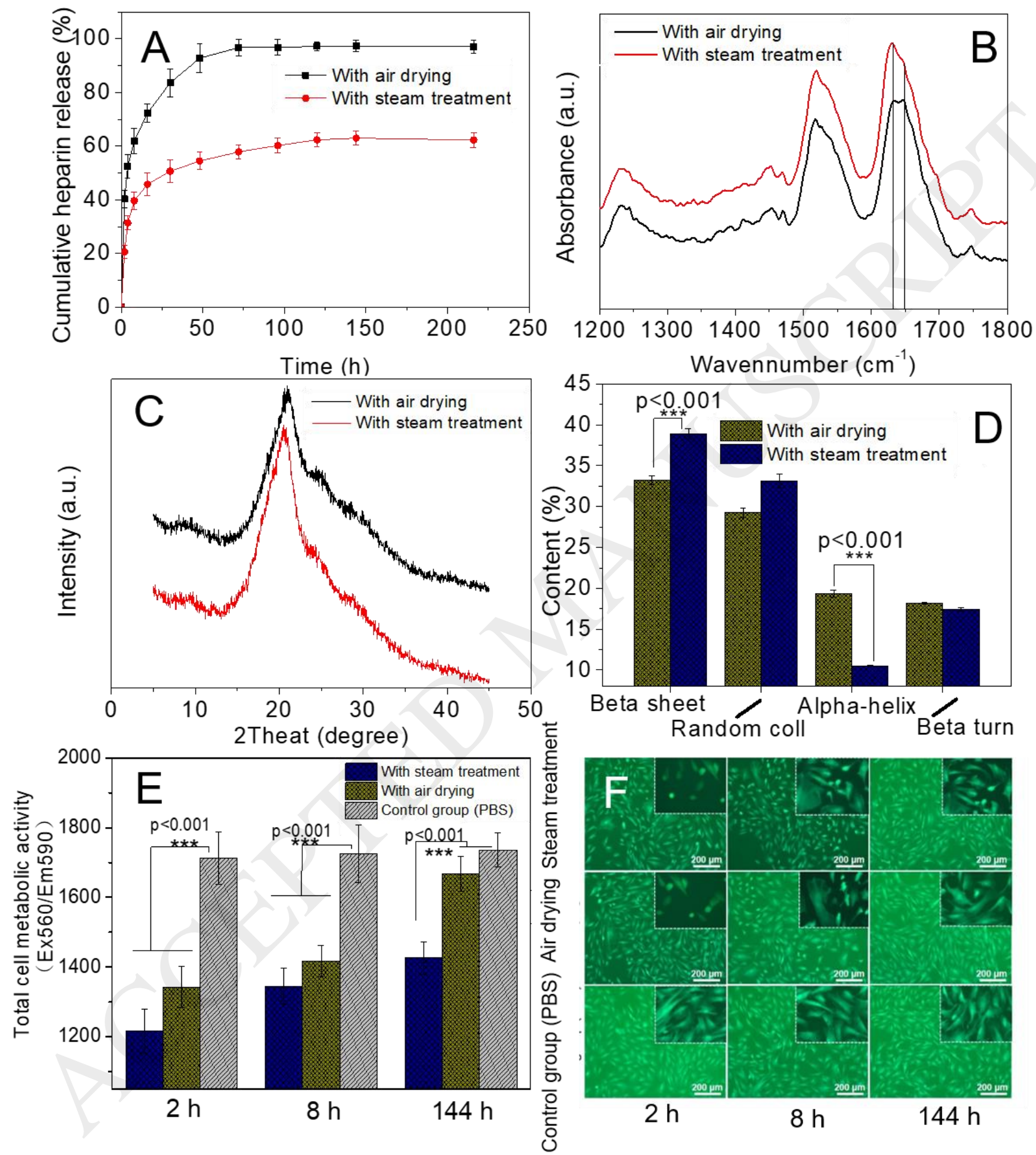

Fig. 7 Heparin release and HVSM cells viability of modified BSGs: (A) Cumulative release of heparin (B) FTIR spectra (C) XRD patterns, (D) secondary structure content of the heparin-modified BSGs, (E) The metabolic activity and (F) fluorescence microscope images of HVSM cells cultured in the release of heparin modified BSGs 
The heparin release $(2 \mathrm{~h})$ of the modified BSGs significantly inhibited cell viability, and a similar inhibiting effect was also found when the release time reached $8 \mathrm{~h}$. When the release medium collected at $144 \mathrm{~h}$ was added to the cell culture, a significant inhibiting effect was still observed for the steam-treated BSGs $(\mathrm{p}<0.001$ ), suggesting the modified BSG with steam treatment had a longer inhibitory effect on HVSM cells in comparison to that of the air-dried BSGs. This result is in agreement with the release study shown in Fig. 7A, where almost no heparin was detected for the air-dried BSGs for the heparin release time of $144 \mathrm{~h}$, whereas $40 \%$ of heparin remained in the modified BSGs with steam treatment. Moreover, the metabolic activity of HVSM cells in the release of modified BSG with steam treatment was even worse than that in the release of the modified BSG with air drying, illustrating that the modified BSGs with steam treatment can inhibit the proliferation of HVSM cells better than that of the air-dried BSGs.

The fluorescence microscope images of HVSM cells cultured in heparin releases are shown in Fig. 7F. Compared to the culture in PBS, where cells are stretched and healthy, cells cultured in the releases of modified BSGs did not spread well and exhibited irregular shapes, indicating the cell viability was decreased. The result is consistent with the findings in Fig. 7E; the proliferation of HVSM cells were effectively inhibited in the presence of the heparin-modified BSGs, as is consistent with previous studies $[45,46]$.

More importantly, the study verified the hypothesis that the modified BSGs with steam treatment is superior than that of the air-dried BSGs in preventing the over-proliferation of HVSM cells; thus, our approach provides a new tool for biomaterial scientists to design and engineer BSGs with seamless 
structure. Compared to the commonly used chemical modification, we utilized SF-assisted physical coating to entrap heparin on the BSG surface, enabling high loading and sustained release of drugs that can be used for stent grafting applications.

\section{Conclusions}

We fabricated SF/heparin-functionalized bifurcated stent-graft (BSG) using textile engineering technology and steam/air treatment to achieve anticoagulant function and to improve the patency of the BSGs. The results showed that the pure SF-based, plain weave BSG $(1100 / 10 \mathrm{~cm} \times 2000 / 10 \mathrm{~cm})$ could adequately meet the requirements of transplantation; thus, our approach provides a new textile-based strategy for the development of vascular prosthesis. Surface modification of BSGs using heparin and SF that was followed by air drying and steam treatment significantly changed the thickness $(\mathrm{p}<0.05)$ and water permeability $(\mathrm{p}<0.01)$ of the device. More sustained release of heparin over $120 \mathrm{~h}$ was achieved for the steam-treated BSG compared with that of the air-dried BSG, indicating that the release of heparin could be controlled owing to the structural transition of SF during steam treatment. The viability of HVSM cells cultured in the release of the steam-treated BSG was significantly inhibited at $144 \mathrm{~h}$ that was longer than that for the air-dried BSG, demonstrating the sustained release of heparin from the modified device. The kinetics of the heparin release of the BSGs requires further investigation. Our work contributes to the development of next-generation vascular prostheses with occlusive capabilities.

\section{Acknowledgements}

This work was supported by the National Natural Science Foundation of China (51603140 and 81603457). The authors would like to thank the support of China Postdoctoral Science Foundation, 
University Science Research Project of Jiangsu Province (16KJB540003) and Science and Technology

Project of Suzhou (SYG201638 and SYG201849) and projects with code 2018914 and 2018054. 


\section{References}

[1] R.H. Bemelmans, Y.V.D. Graaf, H.M. Nathoe, A.M. Wassink, J.W. Vernooij, W. Spiering, F.L. Visseren, Increased visceral adipose tissue is associated with increased resting heart rate in patients with manifest vascular disease, Obesity 20 (2012) 834-841.

[2] S. Rizza, M. Copetti, C. Rossi, M. Cianfarani, M. Zucchelli, A. Luzi, C. Pecchioli, O. Porzio, G.D. Cola, A. Urbani, Metabolomics signature improves the prediction of cardiovascular events in elderly subjects, Atherosclerosis 232 (2014) 260-264.

[3] R.K. Greenberg, T.A.M. Chuter, R.P. Cambria, W.C. Sternbergh, N.E. Fearnot, Zenith abdominal aortic aneurysm endovascular graft, J. Vasc. Surg. 48 (2008) 1-9.

[4] I.F.J. Tielliu, E.L.G.Verhoeven, C.J. Zeebregts, T.R. Prins, B.I. Oranen, J.A.M. Dungen, Endovascular treatment of iliac artery aneurysms with a tubular stent-graft: Mid-term results, J. Vasc. Surg. 43(2006) 440-445.

[5] H.F. Guo, W.W. Dai, D.H. Qian, Z.X. Qin, Y. Lei, X.Y. Hou, C. Wen, A simply prepared small-diameter artificial blood vessel that promotes in situ endothelialization, Acta Biomater. 54 (2017) 107-116.

[6] J.D. Kakisis, C.D. Liapis, C. Breuer, B.E. Sumpio, Artificial blood vessel: the Holy Grail of peripheral vascular surgery, J. Vasc. Surg. 41 (2005) 349-354.

[7] D. Liang, B.S. Hsiao, B. Chu, Functional electrospun nanofibrous scaffolds for biomedical applications, Adv. Drug Delivery Rev. 59 (2007) 1392-1412.

[8] S.C. Kundu, B.C. Dash, R. Dash, D.L. Kaplan, Natural protective glue protein, sericin 
bioengineered by silkworms: potential for biomedical and biotechnological applications, Prog. Polym. Sci. 33 (2008) 998-1012.

[9] G. Li, Y.P. Liu, P. Lan, Y. Li, Y.L. Li, A prospective bifurcated biomedical stent with seamless woven structure, J. Text. Inst. 104 (2013) 1017-1023.

[10]G. Li, F. Li, Z.Z. Zheng, T.T. Luo, J. Liu, J.B. Wu, X.Q. Wang, D.L. Kaplan, Silk microfiber-reinforced silk composite scaffolds: fabrication, mechanical properties, and cytocompatibility, J. Mater. Sci. 51 (2016) 3025-3035.

[11]G. Li, Y. Li, G.Q. Chen, J.H. He, Y.F. Han, X.Q. Wang, D.L. Kaplan, Silk - based biomaterials in biomedical textiles and fiber - based implants, Adv. Healthc. Mater. 4 (2015) 1134-1151.

[12] Y. Chen, X. Ding, Y.L. Li, M.W. King, J. Gao, X.Q. Zhao, A bilayer prototype woven vascular prosthesis with improved radial compliance, J. Text. Inst. 103 (2012) 106-111.

[13]Z. Ma, M. Kotaki, T. Yong, W. He, S. Ramakrishna, Surface engineering of electrospun polyethylene terephthalate (PET) nanofibers towards development of a new material for blood vessel engineering, Biomaterials 26 (2005) 2527-2536.

[14]S. Ravi, E.L. Chaikof, Biomaterials for vascular tissue engineering, Regen. Med. 5 (2010) 107-120.

[15]C. Mao, Y.Z. Qiu, H.B. Sang, H. Mei, A.P. Zhu, J. Shen, S.C. Lin, Various approaches to modify biomaterial surfaces for improving hemocompatibility, Adv. Colloid Interface Sci. 110 (2004) 5-17.

[16]J. Li, B.Q. Zhu, Y.Y. Shao, X.R. Liu, X.L. Yang, Q. Yu, Construction of anticoagulant poly (lactic acid) films via surface covalent graft of heparin-carrying microcapsules, Colloids Surf., B 70 (2009) $15-19$.

[17]G.C. Li, F.M. Zhang, Y.Z. Liao, P. Yang, N. Huang, Coimmobilization of heparin/fibronectin 
mixture on titanium surfaces and their blood compatibility, Colloids Surf., B. 81 (2010) 255-262.

[18]S. Thorslund, J. Sanchez, R. Larsson, F. Nikolajeff, J. Bergquist, $\quad$ Colloids Surf., B 45 (2005) 76-81.

[19]R.J. Pugh, J.B. Slee, S.L.N. Farwell, Y. Li, T. Barthol, W.A. Patton, L.J. Lowekrentz, Transmembrane protein $184 \mathrm{~A}$ is a receptor required for vascular smooth muscle cell responses to heparin, J. Biol. Chem. 291 (2016) 5326-5337.

[20]I.S. Robu, W.H. Rd, H.W. Matthew, Morphological and growth responses of vascular smooth muscle and endothelial cells cultured on immobilized heparin and dextran sulfate surfaces, J. Biomed. Mater. Res., Part A 105 (2017) 1725-1735.

[21]Z.K. Liu, G. Li, Z.Z. Zheng, Y. Li, Y.F. Han, D.L. Kaplan, X.Q. Wang, Silk fibroin-based woven endovascular prosthesis with heparin surface modification, J. Mater. Sci.: Mater. Med. 29 (2018) 46-59.

[22]M.F. Elahi, G. Guan, L. Wang, X. Zhao, F. Wang, M.W. King, Surface modification of silk fibroin fabric using layer-by-layer polyelectrolyte deposition and heparin immobilization for small diameter vascular prostheses, Langmuir 31 (2015) 2517-2526.

[23] M. Elahi, G. Guan, L. Wang, M. King, Influence of layer-by-layer polyelectrolyte deposition and EDC/NHS activated heparin immobilization onto silk fibroin fabric, Materials 7 (2014) 2956-2977.

[24]W. Gong, D. Lei, S. Li, P. Huang, Q. Qi, Y. Sun, Y. Zhang, Z. Wang, Z. You, X. Ye, Hybrid small-diameter vascular grafts: anti-expansion effect of electrospun poly $\varepsilon$-caprolactone on heparin-coated decellularized matrices, Biomaterials 76 (2016) 359-370.

[25] Y. Yao, J.M. Wang, Y. Cui, R. Xu, Z.H. Wang, J. Zhang, K. Wang, Y.J. Li, Q. Zhao, D. Kong, 
Effect of sustained heparin release from PCL/chitosan hybrid small-diameter vascular grafts on anti-thrombogenic property and endothelialization, Acta Biomater. 10 (2014) 2739-2749.

[26]J. Chen, Y. Zhan, Y. Wang, D. Han, B. Tao, Z. Luo, S. Ma, Q. Wang, X. Li, L. Fan, Chitosan/silk fibroin modified nanofibrous patches with mesenchymal stem cells prevent heart remodeling post-myocardial infarction in rats, Acta Biomater. 80 (2018) 154-168.

[27]J. Chen, G. Cheng, R. Liu, Y. Zheng, M. Huang, Y. Yi, X. Shi, Y. Du, H. Deng, Enhanced physical and biological properties of silk fibroin nanofibers by layer-by-layer deposition of chitosan and rectorite, J. Colloid Interface Sci. 523 (2018) 208-216.

[28]G. Wu, H. Deng, T. Jiang, H. Tu, J. Chen, Y. Zhan, Y. Wang, X. Ma, Regulating the gaps between folds on the surface of silk fibroin membranes via LBL deposition for improving their biomedical properties, Colloids Surf., B. 154 (2017) 228-238.

[29]A.S. Lammel, X. Hu, S.H. Park, D.L. Kaplan, T.R. Scheibel, Controlling silk fibroin particle features for drug delivery, Biomaterials 31 (2010) 4583-4591.

[30]E. Wenk, H.P. Merkle, L. Meinel, Silk fibroin as a vehicle for drug delivery applications, J. Controlled Release 150 (2011) 128-141.

[31]Z.K. Liu, G. Li, Y.L. Li, Y. Li, X.Q. Wang, Structural design and fabrication of silk/polyester-based bifurcated stent-graft, J. Fiber Bioeng. Inform. 10 (2017) 211-222.

[32]R. Hajjaji, S.B. Abdessalem, J. Ganghoffer, The influence of textile vascular prosthesis crimping on graft longitudinal elasticity and flexibility, J. Mech. Behav. Biomed. Mater. 16 (2012) 73-80.

[33]X.Y. Peng, H.Q. Luo, N.B. Li, Voltammetric study on the interaction of heparin with toluidine blue, and its analytical application, Microchim. Acta 156 (2006) 297-302. 
[34]S.Z. Lu, L. Feng, M.Z. Li, C.X. Di, L. Bai, Study on silk I porous 3-D scaffolds, Key Engineering Materials, Trans Tech Publ, 2007, pp. 233-236.

[35]X. Hu, D. Kaplan, P. Cebe, Determining beta-sheet crystallinity in fibrous proteins by thermal analysis and infrared spectroscopy, Macromolecules. 39 (2006) 6161-6170.

[36]N. Ashwanikumar, N.A. Kumar, S.A. Nair, G.S.V. Kumar, 5-Fluorouracil-lipid conjugate: Potential candidate for drug delivery through encapsulation in hydrophobic polyester-based nanoparticles, Acta Biomater. 10 (2014) 4685-4694.

[37]F. Lucas, J.T.B. Shaw, S.G. Smith, Amino-acid sequence in a fraction of bombyx silk fibroin, Nature 178 (1956) 861-861.

[38]K.N. Stevens, S. Croes, R.S. Boersma, E.E. Stobberingh, C. van der Marel, F.H. van der Veen, M.L. Knetsch, L.H. Koole, Hydrophilic surface coatings with embedded biocidal silver nanoparticles and sodium heparin for central venous catheters, Biomaterials. 32 (2011) 1264-1269.

[39]J. Kim, C.H. Kim, C.H. Park, J.N. Seo, H. Kweon, S.W. Kang, K.G. Lee, Comparison of methods for the repair of acute tympanic membrane perforations: Silk patch vs. paper patch, Wound Repair Regen. 18 (2010) 132-138.

[40]H.J. Jin, J. Park, V. Karageorgiou, U.J. Kim, R. Valluzzi, P. Cebe, D.L. Kaplan, Water- stable silk films with reduced $\beta$ - sheet content, Adv. Funct Mater. 15 (2005) 1241-1247.

[41]P.S. Damus, M. Hicks, R.D. Rosenberg, Anticoagulant action of heparin, Nature. 246 (1973) 355.

[42]S. Wang, Y. Zhang, H. Wang, Z. Dong, Preparation, characterization and biocompatibility of electrospinning heparin-modified silk fibroin nanofibers, Int. J. Biol. Macromol. 48 (2011) 345-353.

[43]B.D. Lawrence, F. Omenetto, K. Chui, D.L. Kaplan, Processing methods to control silk fibroin film 30 
biomaterial features, J. Mater. Sci. 43 (2008) 6967-6985.

[44]J.B. Wu, Z.Z. Zheng, G. Li, D.L. Kaplan, X.Q. Wang, Control of silk microsphere formation using polyethylene glycol (PEG), Acta Biomater. 39 (2016) 156-168.

[45]C.J. Jr, D.L. Cochran, M.J. Karnovsky, Effect of heparin on vascular smooth muscle cells. I. Cell metabolism, J. Cell. Physiol. 124 (2010) 21-28.

[46]R.A. Majack, A.W. Clowes, Inhibition of vascular smooth muscle cell migration by heparin-like glycosaminoglycans, J. Cell. Physiol. 118 (2010) 253-256. 